\title{
POSTOPERATIVE CORNEAL HAZE AFTER TRANSEPITHELIAL PHOTOREFRACTIVE KERATECTOMY (TRANS PRK) VERSUS CONVENTIONAL PHOTOREFRACTIVE KERATECTOMY (PRK)
}

\author{
By
}

\section{Hosny Hassan Mohammad, Abd El-Magid Mohamed Tag El-Din, Mohammad S. Al-Sheikh*}

Ophthalmology Department, Faculty of Medicine, Al-Azhar University, Cairo, Egypt

*Corresponding author: drmsalsheikh@gmail.com

\begin{abstract}
Background: Photorefractive keratectomy PRK is a refractive surgery appropriate for subjects with refractive errors who are not eligible candidates for laser in situ keratomileusis (LASIK).Transepithelial photorefractive keratectomy (transPRK) is a subtype of PRK in which conventional alcohol assisted mechanical removal of the epithelium is replaced by excimer laser itself. Postoperative corneal haze is a relatively known complication in both techniques.

Objective: To compare between photorefractive keratectomy (prk) and transepithelial photorefractive keratectomy (transPRK) regarding postoperative haze.

Patients and methods: This was a prospective study was conducted on 60 patients (120 eyes) of both sexes. Patients were divided into two equal groups. Group A underwent conventional PRK, and group B underwent transPRK. Postoperative corneal haze evaluation was applied for both groups using slit lamp biomicroscopy.

Results: No statistically significant correlation, but the incidence and degree of haze in the transPRK group were less than PRK group. Visual acuity was slightly better in transPRK group without any statistically significant difference, too.

Conclusion: TransPRK was superior to conventional alcohol assisted PRK especially in moderate and high myopia.

Keywords: PRK, TransPRK, Corneal haze, Haze classification.

\section{INTRODUCTION}

Photorefractive keratectomy (PRK) consists of the application of energy of the ultraviolet range generated by an argon fluoride (ArF) excimer laser to the anterior corneal stroma to change its curvature and, thus, to correct a refractive error. In the late 1990s, transepithelial photorefractive keratectomy (tPRK) was introduced where removal of the

epithelium is carried out with laser phototherapeutic ablation followed by a laser refractive ablation of the stroma. This 2-step technique was not widely used due to the prolonged surgery time with the older generation of lasers, increased pain, and a lack of adjusted nomograms. Transepithelial PRK (tPRK) using Amaris excimer laser is a modified and alternative method to conventional PRK. The unique
\end{abstract}


feature of this technique is that it can be applied as one step, non-touch surgery using the transepithelial PRK nomogram of the Amaris laser with minimum induced trauma to the eye (Fadlallah et al., 2011).

Both techniques remodel corneal stroma to compensate refractive errors. The removal of epithelium and the ablation of stroma provoke the disruption of corneal nerves and a release of several peptides from tears, epithelium, stroma and nerves. Corneal haze, epithelial healing irregularity and pain are known adverse effects of PRK. Corneal haze reduces corneal transparency at variable degrees. Subepithelial haze occurs in all patients 1 month after PRK, reaching the greatest intensity at 3 to 6 months, and gradually decreases from then on. Yet, some authors affirm that it begins to decrease at 12 to 24 months after PRK . Corneal haze has been traditionally measured in the slit-lamp, and graded with diverse scales, like Hanna's scale. The new technology leads us to use automated instruments for corneal haze measurement. In vivo confocal microscopy is a reliable tool, as far as standardized methods are used (Mclaren et al., 2010).

The aim of this work was to compare between photorefractive keratectomy (prk) and transepithelial photorefractive keratectomy (Trans prk) regarding postoperative haze.

\section{PATIENTS AND METHODS}

This was a prospective study was conducted on 60 patients (120 eyes) of both sexes in EYE WORLD HOSPITAL using SHWIND AMARIS 1050RS (manufactured in SCHWIND eye-techsolutions $\mathrm{GmbH}$ Mainparkstraße 61063801 Kleinostheim, Germany), starting from April $1^{\text {st }} 2019$ till June $30^{\text {th }}$ 2019 with the following inclusion \& exclusion criteria:

\section{Inclusion Criteria:}

1. Age range from 20 to 40 .

2. Simple myopia from 1 to 6 diopters.

3. A stable refractive error for at least 12 months before the surgery.

4. Contact lens discontinuation for at least 3 weeks before surgery.

5. Estimated corneal stromal bed thickness of more than $300 \mu \mathrm{m}$ at the thinnest point.

\section{Exclusion Criteria:}

1. Previous ocular surgery.

2. Any diagnosed ocular disease.

3. A history of ocular trauma.

4. Irregular astigmatism on corneal topography.

5. Systemic disease that could affect corneal wound healing, as in diabetes mellitus.

\section{Pregnancy.}

Patients were divided into two equal groups: Group A underwent conventional PRK, and group B underwent trans PRK. Preoperatively all patients gave written consents, had a complete eye examination including uncorrected and best corrected visual acuity, manifest and cycloplegic refraction slit lamp biomicroscopy and applanation tonometry. Intraoperatively povidine iodine scrub was applied to lids and lashes, speculum was placed, 
benoxinate hydrochloride $(0.4 \%)$ drops were instilled.

In group A epithelium was removed with a spatula after administration of $20 \%$ ethyl alcohol for 20 seconds using a sponge, while in group B using the excimer laser itself with optical zone from $6.0 \mathrm{~mm}$. Mitomycin (0.02\%) soaked microsponge was applied for 30 seconds on the ablated area, followed by careful irrigation with balanced salt solution (BSS) and a drop of moxifloxacin was instilled. A soft contact lens was inserted for 5 days till complete re-epithelialization was achieved.

All patients were treated with prednisolone acetate (1\%) for 6 weeks: 5 times daily for two weeks and then tapered by one drop every week for 4 weeks, and moxifloxacin $(0.5 \%) 5$ times daily for the first week. Postoperative corneal haze evaluation was done for both groups using slit lamp biomicroscopy.

\section{Statistical analysis:}

Abstracted data were compiled and analyzed using Statistical Package for Social Sciences, SPSS version 18 (SPSS Inc., Chicago, IL). Continuous variables were presented as means ( \pm standard deviation $[\mathrm{SD}]$ ). Continuous variables were compared using Mann-Whitney test, and categorical data were analyzed using the chi-square test and Yates' continuity correction. Statistical significance established at $\mathrm{p} \leq 0.05$.

\section{RESULTS}

This study included 120 myopic eyes of 60 patients diagnosed with moderate myopia divided equally into two groups; 30 patients were subjected to PRK (14 males and 16 females) with a mean age of 28.70 years and the other 30 were subjected to trans PRK (17 females and 13 males).Patients' ages in both groups ranged from 20 to 40 years, with a mean age of 29.50 years.

No significant difference between the PRK and Trans PRK group regarding degree of haze. In PRK group, mean degree of haze according to US army grading was $0.32 \pm 0.57$, while in Trans PRK group was $0.14 \pm 0.28$. Significant difference between the PRK and Trans PRK groups regarding visual acuity. In PRK group, mean Visual acuity was 0.89 \pm 0.17 , While in Trans PRK group was $0.96 \pm 0.07$ and $P$ value was 0.040 [Table 1]

Table (1): Visual acuity and degree of haze between PRK and T-PRK groups

\begin{tabular}{|l|c|c|c|}
\hline Groups & $\begin{array}{c}\text { Group A } \\
\text { Eyes (N =60) }\end{array}$ & $\begin{array}{c}\text { Group B } \\
\text { Eyes (N=60) }\end{array}$ & P value \\
\hline $\begin{array}{c}\text { Degree of haze according } \\
\text { to US army grading }\end{array}$ & $0.32 \pm 0.57$ & $0.14 \pm 0.28$ & 0.171 \\
\hline Visual acuity & $0.89 \pm 0.17$ & $0.96 \pm 0.07$ & 0.040 \\
\hline
\end{tabular}




\section{DISCUSSION}

In this study it was tried to find a correlation between the technique of epithelium removal \& corneal haze regarding incidence \& degree by evaluating haze postoperatively using slit lamp biomicroscopy according to the US army surface ablation grading system, trying to neutralize other possible factors especially age and corrected error.

Although results showed no statistically significant correlation but still the incidence \& degree of haze in the trans prk group are less than prk group. Visual acuity was slightly better in trans prk group with no statistically significant difference, too.

Suggested explanation is that wounding the epithelium by excimer laser is less insulting, more regular and more accurate than conventional alcohol assisted method as it produces minimal trauma and performs the debridement in a relatively brief and standardized interval reducing concern about stromal fluidly. It also provides a more smoothly basement surface for PRK ablation which can promote the adherency and transmigration of epithelium and decrease hyperplasia of fibroblast in ground substance, thus improves the recovery of the visual acuity theoretically .In addition, using excimer laser creates a smaller, healthier, and neater epithelial edge.

Visual outcomes were close in both groups despite slightly different haze grades as early grades of haze found in most cases with haze, 0.5 and 1 grades didn't significantly affect the visual acuity. No enough studies have been held investigating this point so far, and results of the few ones already have been carried out were similar. Dong-Mei et al. (2012) showed no significant difference in haze value at one month but significant reduced haze value was present at 3 months. Waleed et al, (2014) showed that haze was not a significant issue as it is not exceeding score 2 and regressed in all patients to less than grade 1 by the end of the study.

Ioannis and his co-authors (2015) found reduced haze formation compared to alcohol-assisted PRK using single-step trans PRK for lower degrees of correction with routine use of MMC, given the expected higher risk of haze with deeper ablations and the fact that the study was conducted in the island of Crete, an area with high intensity of sunlight.

In our study, the percentage was $22 \%$. This relatively high percentage could be due to lower number of patients and all refractive errors were of one type. Kaisarman and his colleagues (2017) worked on a higher scale, included hyperopia, and classified myopia into low to moderate and high simple myopia. They reported haze of $2.1 \%$ for high myopia, $1.1 \%$ for low to moderate myopia and $10 \%$ for hyperopia.

\section{CONCLUSION}

Trans PRK was superior to conventional alcohol assisted PRK especially in moderate and high myopia.

\section{REFERENCES}

1. Dong-Mei W., Yi D., Guang-Sheng C., Liusung $T$. and Jian-Feng H. (2012): Transepithelial photorefractive keratectomy mode using Schwind -Esiris excimer laser. Int J Ophthalmol. 5 (3):24-25.

2. Fadlallah A., Fahed D., Khalil K., Dunia I., Menassa J., El Rami H., Chlela E. and Fahed S. (2011): Transepithelial 
photorefractive keratectomy: Clinical results. J Cataract Refract Surg, 37:1852-1857.

3. Ioannis M., Panagiotis N., Vasilis D. and Achyut N. (2015): Single-step transepithelial ASLA (SCHWIND) with mitomycin-C for the correction of high myopia: Long term follow-up. Clinical Ophthalmology Journal, 9:33-41.

4. Kaiserman I., Sadi N., Mimouni M., Sela T., Munzer G. and Levartovsky S. (2017): Corneal Breakthrough Haze After Photorefractive Keratectomy with Mitomycin C: Incidence and Risk Factors. Cornea, 36 (8): 961-966.
5. McLaren W., Bourne M. and Patel V. (2010): Automated Assessment of Keratocyte Density in Stromal Images from the ConfoScan 4 Confocal Microscope. Invest Ophthalmol Vis Sci. 918-1926.

6. Waleed A., Mohammad E. and Kareem A. (2014): Transepithelial photorefractive keratectomy versus conventional alcohol assisted photorefractive keratectomy for correction of mild \& moderate myopia. Journal of Egyptian Ophthalmological Society, 107:1-4. 


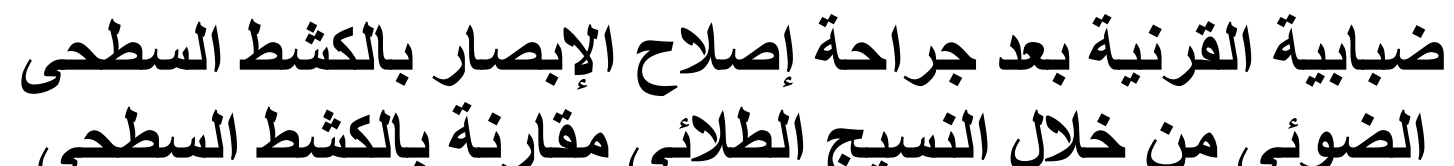
الضوئح بعد إزالة النسيج الطلائى مئى

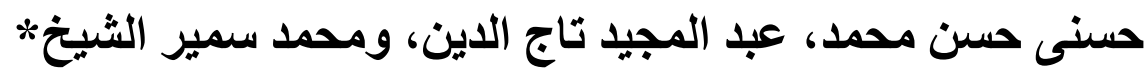
قسم طب وجراحة العيون، كلية الطب، جامعة الأزهر، القاهرة، مصر

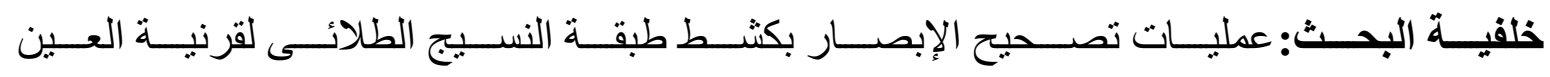

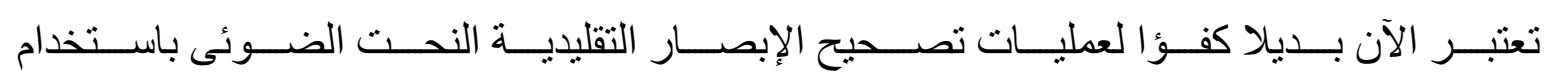
ليزر الإكسيمر (ليزك).

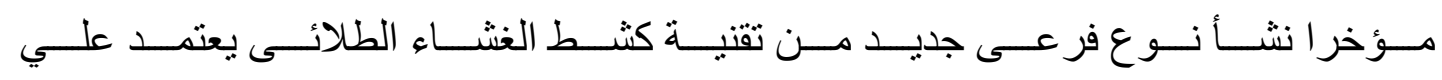

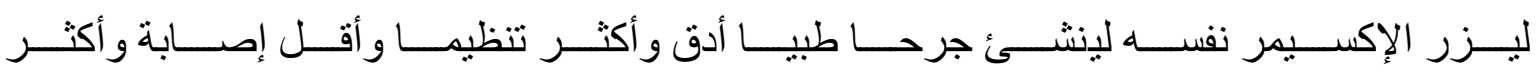
إثقانا.

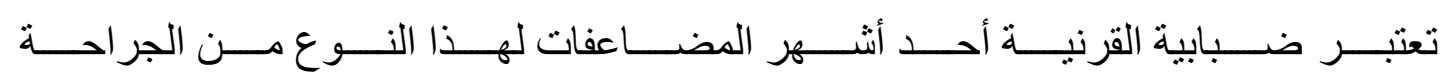
بالطريقة التقليدية و الطريقة المستحدثة.

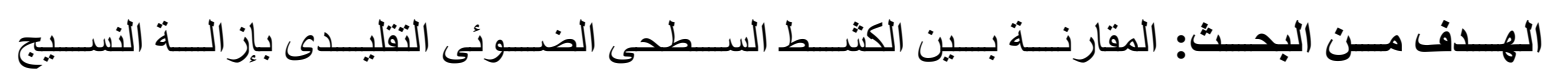

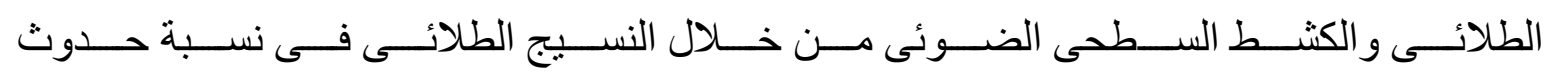
ضبابية القرنبة.

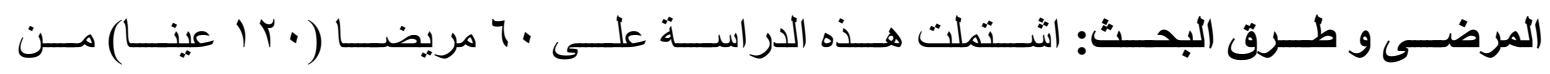

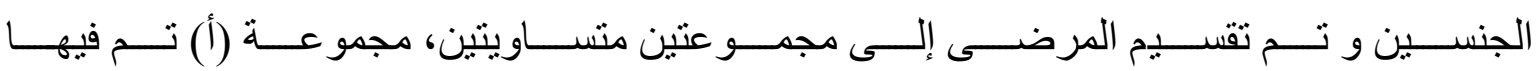

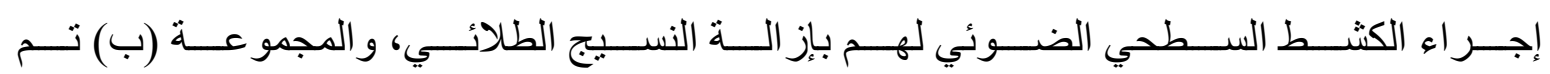
فيها إجر اء الكثط السطحي الضوئي لهم من خلال النسيج الطلائي.

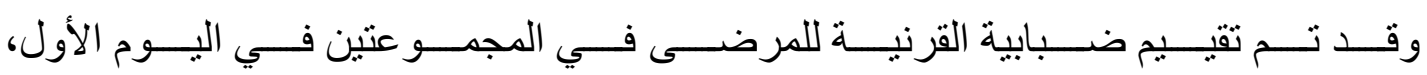

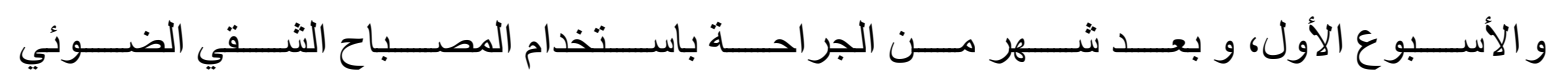
وبالاستعانة بنظام تقييم ضبابية القرنية. 


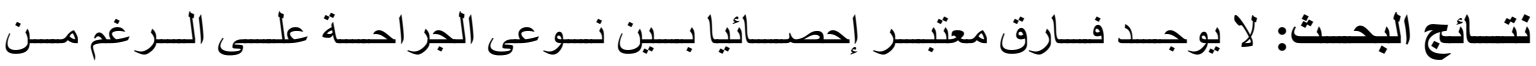

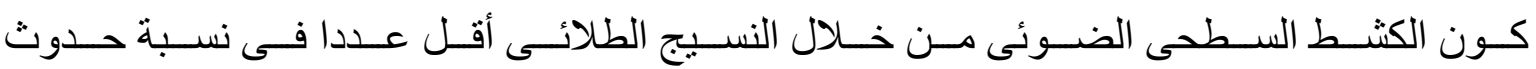
الضبابية و أفضل فى النتيجة النهائية لحدة الإبصار.

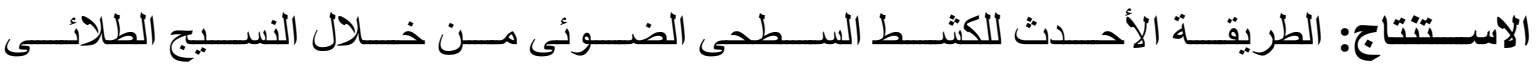

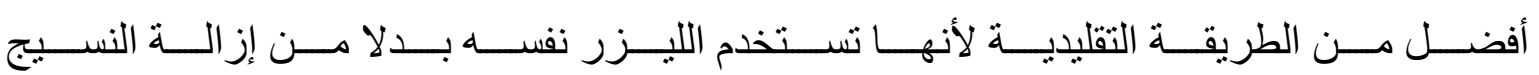

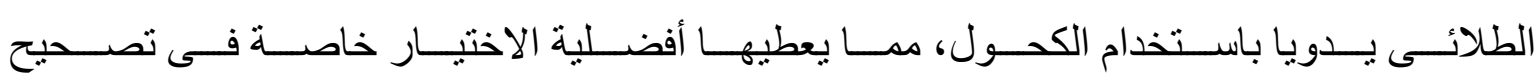
حالات قصر النظر المتوسطو الثديد.

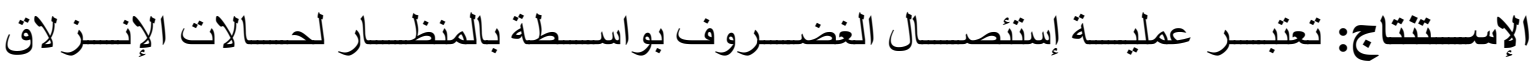

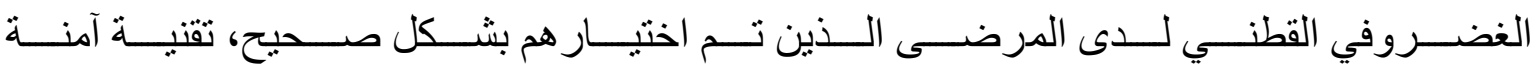

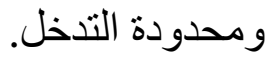

